\title{
Antiparasitic effect of synthetic aromathecins on Leishmania infantum
}

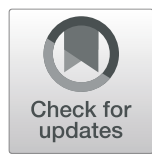

\author{
Rosa M. Reguera', Raquel Álvarez-Velilla', Bárbara Domínguez-Asenjo', Camino Gutiérrez-Corbo', \\ Rafael Balaña-Fouce', Mark Cushman ${ }^{2}$ and Yolanda Pérez-Pertejo ${ }^{1 *}$ (i)
}

\begin{abstract}
Background: Canine leishmaniasis is a zoonotic disease caused by Leishmania infantum, being the dogs one of the major reservoirs of human visceral leishmaniasis. DNA topology is a consolidated target for drug discovery. In this regard, topoisomerase IB - one of the enzymes controlling DNA topology - has been poisoned by hundreds of compounds that increase DNA fragility and cell death. Aromathecins are novel molecules with a multiheterocyclic ring scaffold that have higher stability than camptothecins.

Results: Aromathecins showed strong activity against both forms of L. infantum parasites, free-living promastigotes and intra-macrophagic amastigotes harbored in ex vivo splenic explant cultures obtained from infected BALB/C mice. However, they prevented the relaxation activity of leishmanial topoisomerase IB weakly, which suggests that the inhibition of topoisomerase IB partially explains the antileishmanial effect of these compounds. The effect of aromathecins was also studied against a strain resistant to camptothecin, and results suggested that the trafficking of these compounds is not through the ABCG6 transporter.
\end{abstract}

Conclusions: Aromathecins are promising novel compounds against canine leishmaniasis that can circumvent potential resistances based on drug efflux pumps.

Keywords: Leishmania, DNA-topoisomerase IB, Camptothecin, Aromathecins

\section{Background}

Canine leishmaniasis (CanL) is a serious zoonotic disease caused by $L$. infantum in the Old World and L. infantum chagasi in the New World. Dogs affected by this disease become reservoirs of human visceral leishmaniasis, being extremely relevant the presence of $L$. infantum as its subspecies in Latin America, mainly in Brazil. Although there are several vaccines in use, and preventive measures including collars impregnated with insecticide or spot-on drops contribute to reduce the endemicity of this disease, the use of drugs is strictly necessary when the signs and symptoms appear in the animal. Nowadays, antimony-based $\left(\mathrm{Sb}^{\mathrm{V}}\right)$ drugs, alone or in combination with allopurinol, are considered the gold standard treatment against CanL in southern European countries, whereas the oral drug miltefosine is used as second-line drug [1]. However, the mandatory parenteral administration

\footnotetext{
* Correspondence: myperp@unileon.es

'Departamento de Ciencias Biomédicas, Universidad de León, Campus de

Vegazana s/n; 24071 León (SPAIN), León, Spain

Full list of author information is available at the end of the article
}

of $\mathrm{Sb}^{\mathrm{V}}$ and the multiple side effects of $\mathrm{Sb}^{\mathrm{III}}$ (product of enzymatic activation of the drug by host enzymes), are some of the causes of treatment interruption, which favors the emergence of relapses in the first-year post-treatment. Related to drug misuse is the emergence of resistant strains that may be triggered by host or parasite factors. Among the factors linked to the host, the most prevalent are those related to the alterations of pharmacokinetic parameters or the immunological system. On the other hand, factors related to parasites include structural modifications of target proteins, along with overexpression of $\mathrm{ABC}$ and multiple drug resistance (MDR) proteins [2]. Therefore, drug discovery research in this field is absolutely necessary to find new drugs for the management of CanL.

DNA topoisomerases are consolidated targets for drug development in cancer and infectious diseases. DNA topoisomerase IB (TopIB) is involved in relaxing supercoiled DNA by a DNA breaking and rejoining process. In this process TopIB cleaves one DNA strand by nucleophilic attack from the catalytic tyrosine placed in the active site, which becomes linked to $3^{\prime}$ phosphate end of 
DNA generating a reversible DNA-enzyme cleavage complex. The unbroken strand rotates through the gap and finally the DNA backbone is rejoined [3]. Leishmania TopIB (LTopIB) is interesting from a therapeutic point of view due to its heterodimeric structure, which is dissimilar to the monomeric Top IB found in the rest of animal species [4]. TopIB inhibitors have been classified as TopIB poisons and TopIB inhibitors. TopIB poisons, such as camptothecin (CPT) and other non-CPT compounds like indenoisoquinolines, are anticancer drug leads $[5,6]$, and several reports have shown their efficacy as trypanocide [7] and leishmanicide drugs [8]. These TopIB poisons trap the cleavage complex preventing the final step of rejoining, intercalating into the DNAenzyme complex and generating single strand breaks that evolve to double strand breaks when the replication fork collides with the stabilized cleavage complex [3]. On the other hand, TopIB inhibitors do not stabilize the cleavage complex; they inhibit the enzyme, preventing its binding with DNA by the interaction with the enzymatic catalytic domains or with the DNA substrate [3].

Aromathecins are a new class of TopI poisons, described as stable hybrids of indenoisoquinolines and camptothecins that also show similarity to the natural product luotonin A, which is a weaker TopIB poison [9] (Fig. 1). Several series of modified and substituted luotonins have been published and some analogues have greater antiproliferative activity than the parent compound. 22-Hydroxyacuminatine [10], a rare natural product, contains the $12 \mathrm{H}-5,11 \mathrm{a}$-diazadibenzo [b, h] fluoren11-one system, which is known as "rosettacin" (Fig. 1). Rosettacin derivatives generate aromathecins, which are more stable than camptothecins and maintain lower, but mensurable, topoisomerase poisoning activity [11] (Fig. 1). Further structure-activity studies revealed some trends about these compounds, such as substitutions at C-14 that have been related to an increased anti-cancer activity [1113] or the ethylenedioxy bridge between $\mathrm{C}-2$ and $\mathrm{C}-3$ that has been associated with an enhanced antitrypanosomal activity [14].

The only TopIB inhibitors FDA approved (irinotecan and topotecan) are CPT analogs. These compounds have several limitations as chemical instability of the CPT alpha-hydroxy-lactone ring and loss of efficacy due to the drug efflux-mediated resistance generation [6]. Therefore, it is necessary the development of new nonCPT TopIB inhibitors that overcome these limitations such as aromathecins.

In Leishmania have been described two mechanisms of CPT resistance using strains exposed to increasing concentrations of CPT. The first one involves overexpression of the ABCG6 transporter [15]; the other

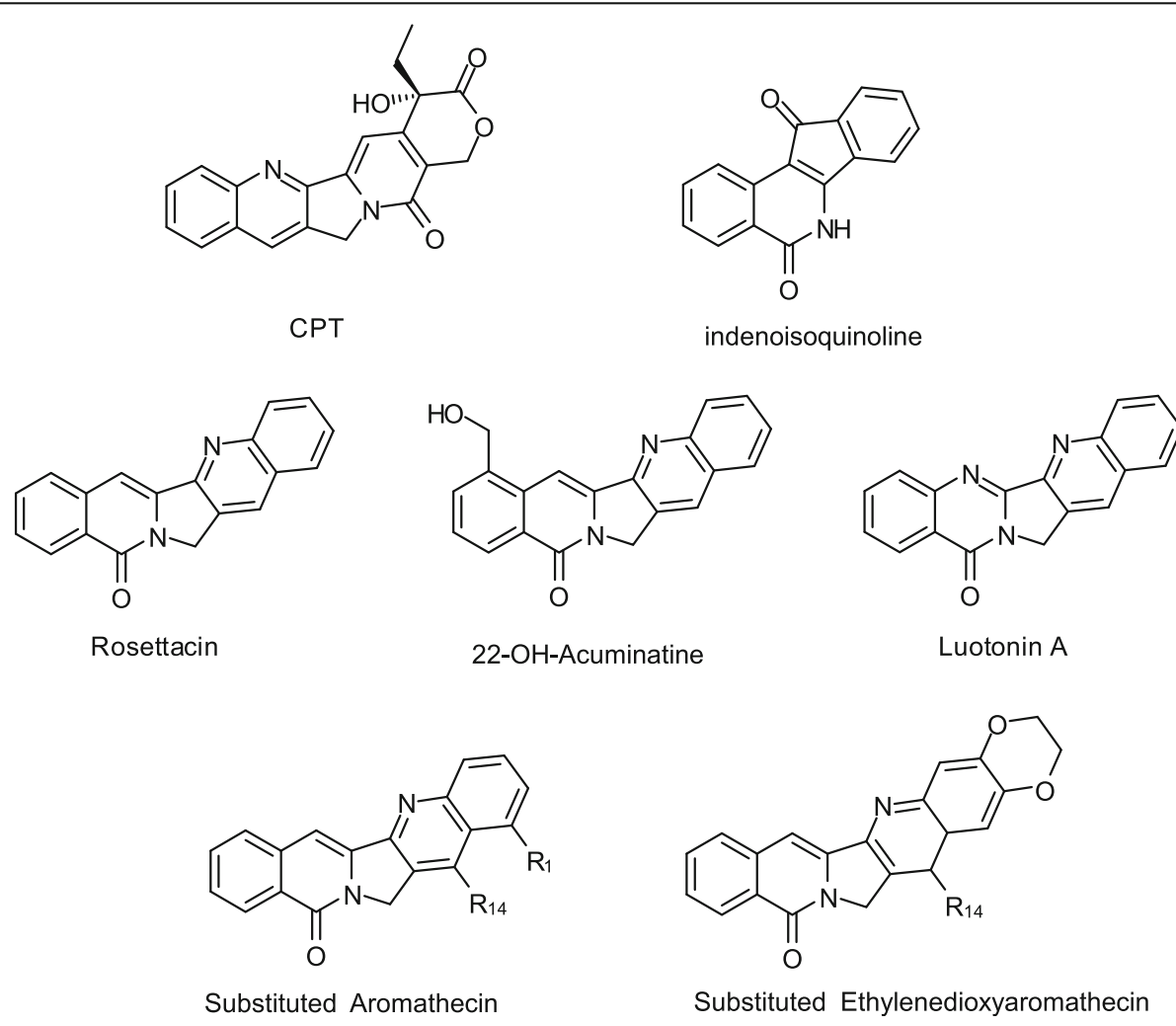

Fig. 1 Chemical structure of ToplB poisons. CPT, indenoisoquinoline scaffold, natural aromathecin-like compounds: Rosettacin, Luotonin A and 22-OH-Acumanetin; synthetic aromathecins used in the current work with relevant positions numbered 
mechanism presumes the amino acid substitutions Gly185Arg and Asp325Glu in the large subunit of the LTopIB enzyme [16]. In mammalian cells the drug efflux pump involved in CPT resistance is the ABCG2 transporter and it has been described that indenoisoquinolines are poor substrates for this transporter besides the multiple drug resistance (MDR)-1 protein [17].

In this report, we describe the antileishmanial activity of two series of aromathecins, which have been kindly provided by Dr. Mark Cushman (Dpt. of Medicinal Chemistry, Purdue University, Indiana, USA), against both stages of $L$. infantum; free-living promastigotes and intra-macrophagic amastigotes present in splenic explants obtained from infected BALB/c mice. In addition, it was assessed their activity as LTopIB inhibitors and their ability to overcome the transporters involved in CPT resistance.

\section{Results}

Two series of aromathecins (Table 1) have been tested against both stages of L. infantum, free-living promastigotes and intracellular amastigotes harbored in mouse splenic cells. Experiments were carried out using a genetically modified $L$. infantum strain that constitutively produces the iRFP protein. This makes it possible to evaluate the viability of parasites measuring the fluorescence emitted at $708 \mathrm{~nm}$ [18].

In order to enhance the antiproliferative activity and TopIB inhibition, the aromathecins used in this study include different substituents (amines, amino alcohols and nitrogenous heterocycles) at the $\mathrm{C}-14$ position which adding solubility and stability to the DNA-enzyme complex [11] (Table 1). In addition, four of them contain an ethylenedioxy bridge (between $\mathrm{C}-2$ and $\mathrm{C}-3$ ) in the Aring (aromathecins 7, 8, 9 and 10) which is aimed at improving the TopIB inhibitory activity of these compounds [13] (Table 1). Interestingly, all the compounds tested in this work showed lower $\mathrm{EC}_{50}$ values in amastigotes than in promastigotes within the micromolar to submicromolar range. Interesting SI values $(>9)$ were found for compounds $\mathbf{1}, \mathbf{8}$ and 10. The ethylenedioxy bridge does not seem to exert a significant effect on the antileishmanial potency.

In addition to the antileishmanial effect of these compounds, their activity as LTopIB inhibitors was analyzed in vitro (Fig. 2). Recombinant LTopIB was produced in a TopIB-defective yeast platform, and purified by standard chromatographic protocols [20]. The effect of aromathecins (comp. 1 to 10) on LTopIB was addressed by measuring the relaxation of negatively supercoiled pBluescript-SK DNA plasmid in the presence of different concentrations of these molecules. In order to separate the nicked DNA generated by the cleavage-complex stabilization from the relaxed topoisomers, gels were run in the presence of ethidium bromide. Five compounds $(1,3,4,5$ and 7) showed a partial inhibition of LTopIB, which started at a very low concentration $(0.01 \mu \mathrm{M})$ and was not concentration dependent. Only a weak band of nicked DNA could be observed with compound $\mathbf{8}$, suggesting that these compounds would act as LTopIB inhibitors rather than poisons. The total inhibition of the enzyme was only observed at a high concentration $(100 \mu \mathrm{M})$ of aromathecins 3, 7 and 9; in addition, compounds $\mathbf{6}$ and $\mathbf{1 0}$ did not have any inhibitory effect, indicating that other targets may be involved.

In order to evaluate if aromathecins would share the transporter involved in CPT resistance, one of the major problems related to the loss of effectiveness of CPT derivatives, a CPT-resistant strain was generated. The CPT-resistant strain used was generated by the exposure of $L$. infantum promastigotes to increasing concentrations of CPT, from 0.1 to $20 \mu \mathrm{M}$ (CPT-20, from now on). CPT-20 showed cross-resistance to other CPT derivatives poisons, such as topotecan $\left(\mathrm{EC}_{50}>100 \mu \mathrm{M}\right.$ vs $\mathrm{EC}_{50}=9.54 \pm 0.22 \mu \mathrm{M}$ in the WT strain) and $\mathrm{SN} 38$ $\left(\mathrm{EC}_{50}=40.98 \pm 0.3 \mu \mathrm{M}\right.$ vs $\mathrm{EC}_{50}=4.73 \pm 0.14 \mu \mathrm{M}$ in the WT strain). Amplification and sequencing of the LTopIBencoding genes from CPT-20 and WT strains showed no differences between them. Therefore, it is very likely that the resistance mechanism of CPT-20 is related to the overexpression of the ABCG6 transporter previously described as the drug-efflux pump involved in the CPT resistance mechanism [15]. The CPT-20 strain was susceptible to the aromathecins assayed in this work $(2,5$ and $\mathbf{1 0}$ were not assayed due to their poor effect against iRFP $L$. infantum promastigotes), showing very similar $\mathrm{EC}_{50}$ values to those obtained with iRFP L. infantum.

\section{Discussion}

All aromathecins tested have shown leishmanicidal activity with stronger effect over the intracellular amastigote form. Aromathecins have been designed as inhibitors of TopIB enzyme and their mechanism of action would be mediated by the stabilization of the intermediate cleavage-complex [11-13]. However, the results obtained in this work indicate that most of these compounds would act as LTopIB inhibitors rather than LTopIB poisons, due to only with compound $\mathbf{8}$ we can observe nick DNA from cleavage-complex stabilization.

Unlike the results obtained with $T$. brucei [14], the ethylenedioxy bridge does not seem to exert a significant effect on the antileishmanial potency. Besides, this bridge does not seem to improve the LTopIB inhibitory activity, especially when we compare the activity of compounds $\mathbf{1}$ and 9, with the same substitution at C-14 position. The inhibition of LTopIB with compound 9 that has the ethylene bridge only happed at a high concentration whilst compound $\mathbf{1}$ inhibit the enzyme at very low concentrations. 
Table 1 Bioactivity of aromathecines on iRFP-L. infantum promastigotes and splenic-infecting amastigotes. Each point represents the average of three different experiments by duplicate

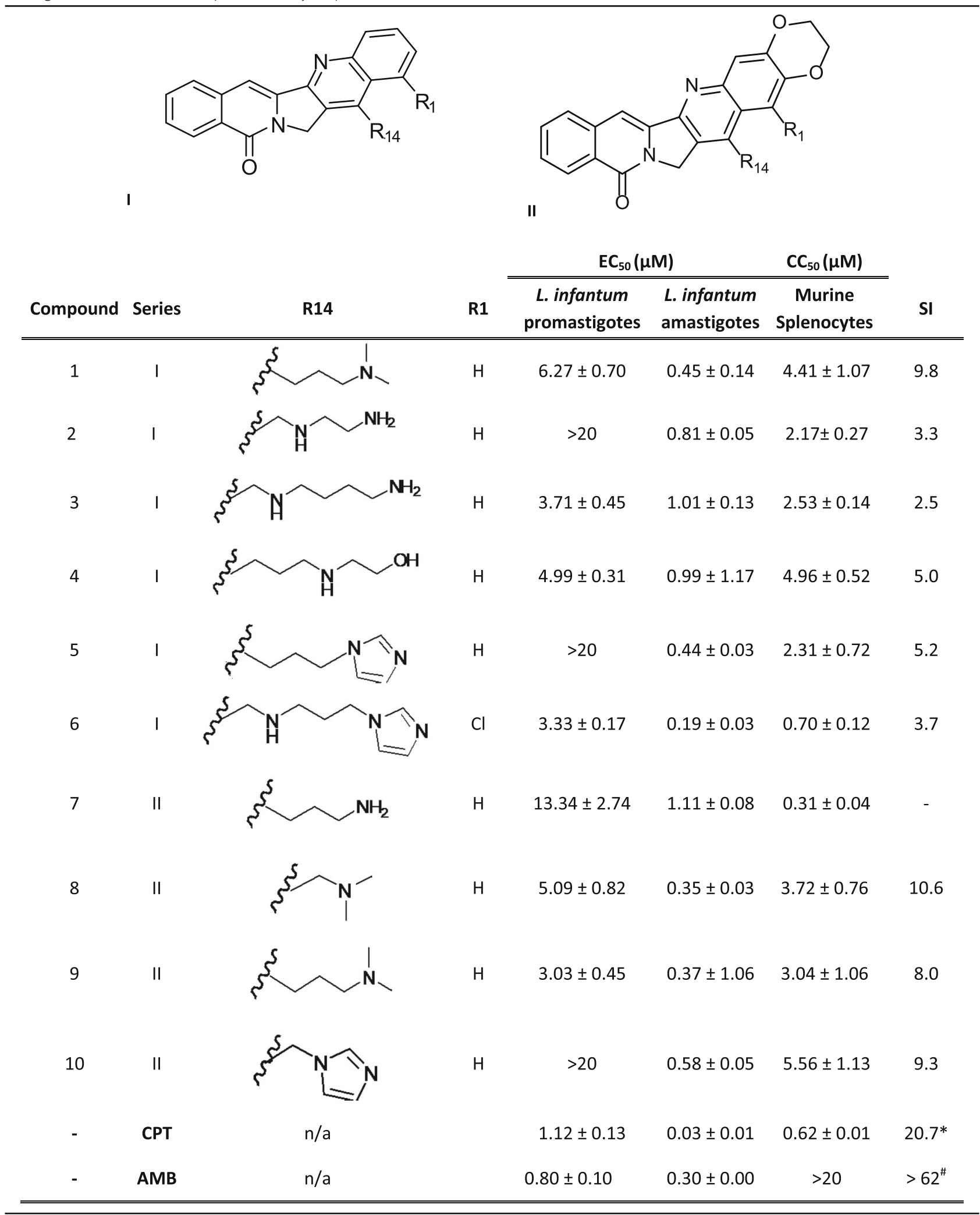

SI: Selectivity Index $=\mathrm{CC}_{50} / \mathrm{EC}_{50}$ (amastigotes)

* See reference [8]

\# See reference [19] 


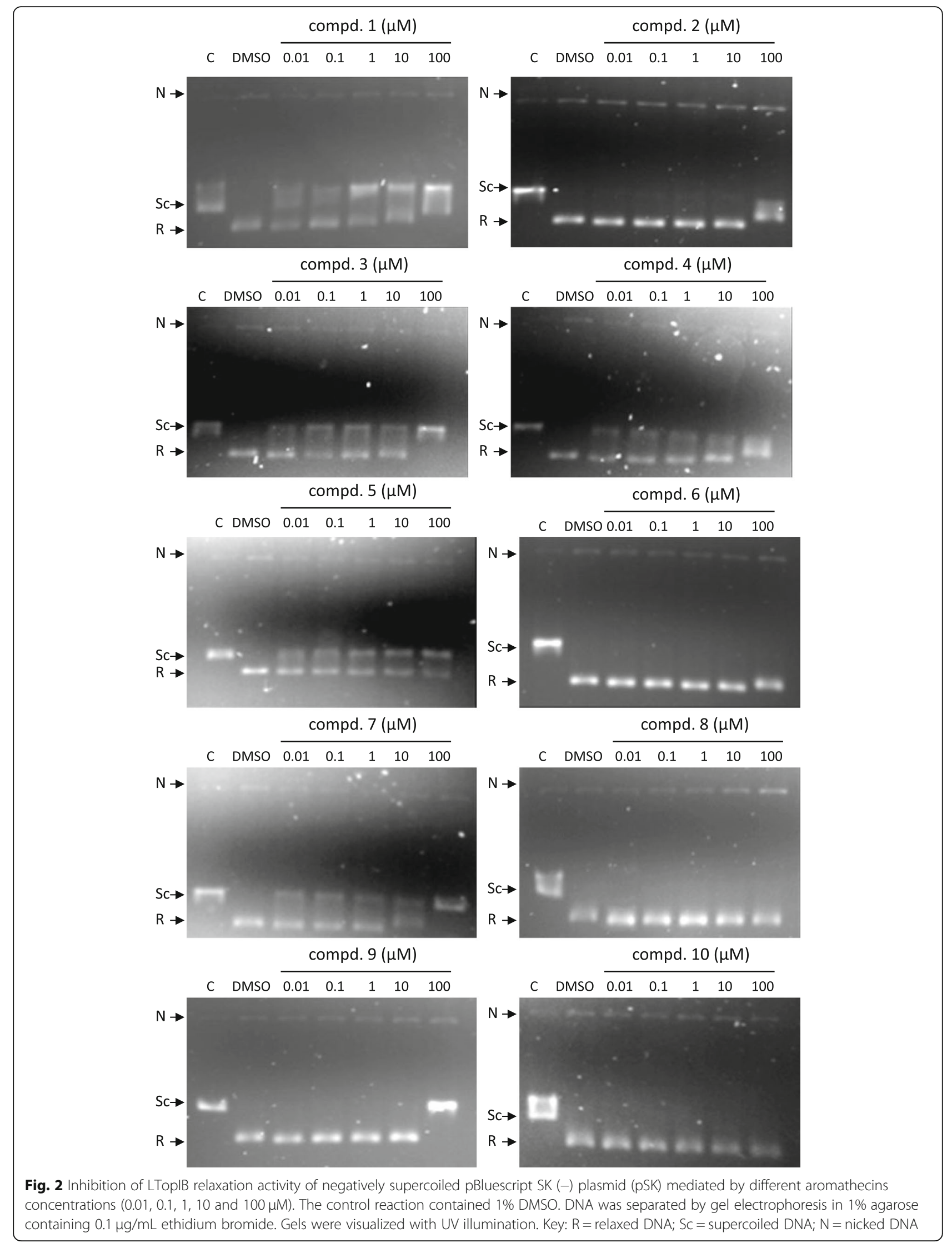


The leishmanicidal activity of compounds $\mathbf{6}$ and 10, which do not have LTopIB inhibitory activity, along with the partial inhibition of the enzyme observed with other compounds indicates that other targets may be involved.

The CPT resistant strain generated in this work by exposition to increased CPT concentrations was susceptible to all the aromathecins tested. These results indicate that aromathecins overcome the ABCG6 transporter, the pump responsible of CPT resistance generation in Leishmania [15]. Similar results have been obtained with other non-camptothecin compounds as indenoisoquinolines, which overcome the ABCG2 transporter involved in CPT resistance in mammalian cells, and the multiple drug resistance (MDR)-1 protein [17].

\section{Conclusions}

In conclusion, the aromathecins tested in this work showed a good antileishmanial activity. These results suggest the existence of another mechanism of action complementary to the expected LTopIB poisoning. Structural differences of LTopIB and the mammalian enzyme could explain this behavior. These differences could be used to design new molecules with improved selectivity, whose advantage lies in overcoming the transporter involved in the generation of $\mathrm{CPT}$ resistance.

\section{Methods}

\section{In vitro $L$. infantum promastigotes assay}

The antiparasitic activity of the compounds was assessed on the genetically modified iRFP $L$. infantum strain, which constitutively produces the infrared fluorescent protein (iRFP) when cells are viable [18]. iRFP L. infantum was grown at $26^{\circ} \mathrm{C}$ in M-199 medium (Gibco) supplemented with $25 \mathrm{mM}$ HEPES pH 7.2, $0.1 \mathrm{mM}$ adenine, $0.0005 \%(\mathrm{w} / \mathrm{v}$ ) hemin, $2 \mu \mathrm{g} / \mathrm{mL}$ biopterin, $0.0001 \%(\mathrm{w} / \mathrm{v})$ biotin, $10 \%(\mathrm{v} / \mathrm{v})$ heat-inactivated fetal bovine serum (FBS) and an antibiotic cocktail comprising $50 \mathrm{U} / \mathrm{mL}$ penicillin and $50 \mu \mathrm{g} / \mathrm{mL}$ streptomycin.

\section{Ex vivo murine splenic explant culture}

Primary splenocyte cultures containing intramacrophagic amastigotes were obtained from dissected spleens of female $\mathrm{BALB} / \mathrm{c}$ mice infected intraperitoneally with $1.5 \times 10^{9}$ metacyclic iRFP L. infantum promastigotes, 5 weeks before their sacrifice. Mice were obtained commercially (Janvier-Labs). Animals were housed in specific-pathogen free facilities and they were euthanized by cervical dislocation without anesthesia. These protocols were approved by the Animal Care Committee of University of Leon (project license SAF2017-83575-R), which complies with European Union Legislation (2010/ 63/UE) and Spanish Act (RD 53/2013).

The spleens were washed with cold phosphatebuffered saline (PBS), cut in small pieces and incubated for $20 \mathrm{~min}$ with $5 \mathrm{~mL}$ of $2 \mathrm{mg} / \mathrm{mL}$ collagenase D (Sigma) prepared in buffer (10 mM HEPES, $\mathrm{pH} 7.4,150 \mathrm{mM}$ $\mathrm{NaCl}, 5 \mathrm{mM} \mathrm{KCl}, 1 \mathrm{mM} \mathrm{MgCl} 2$ and $1.8 \mathrm{mM} \mathrm{CaCl}_{2}$ ). After that, the cell suspension obtained was passed through a $100 \mu \mathrm{m}$ cell strainer, harvested by centrifugation $\left(500 \times \mathrm{g}\right.$ for $7 \mathrm{~min}$ at $4{ }^{\circ} \mathrm{C}$ ), washed twice with PBS, and cultured at $37^{\circ} \mathrm{C}$ under $5 \% \mathrm{CO}_{2}$ atmosphere in RPMI medium (Gibco) supplemented with $10 \mathrm{mM}$ HEPES, $1 \mathrm{mM}$ sodium pyruvate, 1xRPMI 1640 vitamin mix, $10 \%(\mathrm{v} / \mathrm{v}) \mathrm{FBS}, 50 \mathrm{U} / \mathrm{mL}$ penicillin and $50 \mu \mathrm{g} / \mathrm{mL}$ streptomycin (Calvo-Álvarez et al., 2015).

\section{Cytotoxicity and selectivity index determination}

The viability of cultured parasites in the presence of different concentrations of aromathecins was determined by measuring the reduction of infrared fluorescence emitted by free-living promastigotes/amastigotes with respect to negative controls of each form of the parasite treated with DMSO (up to $0.1 \%$ final concentration) as a vehicle. Thus, in order to calculate $\mathrm{EC}_{50}$ value, promastigotes or splenic mouse explants, which harbored amastigotes, were incubated with 7 different concentrations of each aromathecin starting from $100 \mu \mathrm{M}$ and one-third dilutions up to $0.13 \mu \mathrm{M}$ in duplicate and in three independent experiments. After $72 \mathrm{~h}$ incubation at $26^{\circ} \mathrm{C}$, the infrared fluorescence emitted at $708 \mathrm{~nm}$ by viable promastigotes/amastigotes was measured in an Odyssey (LiCor) infrared imaging system. Similarly, the cytotoxic effect $\left(\mathrm{CC}_{50}\right)$ of aromathecins on uninfected splenic explants from BALB/c mice (cells that naturally harbor the amastigote stage) was measured by the Alamar Blue (Invitrogen) assay. The selectivity index (SI) was determined as the relationship between the $\mathrm{CC}_{50}$ value and the $\mathrm{EC}_{50}$ value for amastigotes. $\mathrm{CC}_{50}$ and $\mathrm{EC}_{50}$ were calculated by nonlinear analysis using the Sigma-Plot 10.0 statistical package. The aromathecins were dissolved in DMSO and stored at $-20{ }^{\circ} \mathrm{C}$ before their use as fresh aliquots.

\section{Leishmanial TopIB purification}

Expression and purification of LTopIB were carried out according to a previously standardized protocol [20]. LTopIB was purified from yeast strain EKY3 deficient in TopIB activity $[M A T \alpha$, ura $3-52$, his $3 \Delta 200$, leu $2 \Delta 1$, trp1 $\triangle 63$, top $1 \triangle: T R P 1]$, transfected with the pESC-URA plasmid containing both subunits of LTopIB. Cells were grown in yeast synthetic drop-out medium without uracil (Sigma) supplemented with $2 \%$ raffinose $(\mathrm{w} / \mathrm{v})$ to $\mathrm{OD}_{600}: 0.8-1$ and induced for $10 \mathrm{~h}$ with $2 \%$ galactose $(\mathrm{w} /$ v). Yeast were harvested, washed with cold TEEG buffer (50 mM Tris- $\mathrm{HCl}$ pH 7.4, $1 \mathrm{mM}$ EDTA, $1 \mathrm{mM}$ EGTA, $10 \%$ glycerol) and resuspended to their lysis in $15 \mathrm{~mL}$ of $1 \mathrm{x}$ TEEG buffer supplemented with $0.2 \mathrm{M} \mathrm{KCl}$ and a protease inhibitors cocktail (Thermo Scientific). Protein extract obtained was loaded on a $5 \mathrm{~mL}$ P-11 phosphocellulose 
column (Whatman International Ltd. England). LTopIB protein was eluted at $4{ }^{\circ} \mathrm{C}$ with a discontinuous gradient of $\mathrm{KCl}(0.2,0.4,0.6 \mathrm{M})$ in TEEG buffer.

\section{TopIB relaxation activity assay}

The effect of aromathecins on recombinant LTopIB was determined by measuring the relaxation of negatively supercoiled pBluescript-SK DNA plasmid (pSK). Thus, $20 \mu \mathrm{L}$ of reaction mixture $(0.5 \mu \mathrm{g}$ pSK; $10 \mathrm{mM}$ Tris- $\mathrm{HCl}$ $\mathrm{pH} 7.5 ; 5 \mathrm{mM} \mathrm{MgCl} 2 ; 0.1 \mathrm{mM}$ EDTA; $15 \mu \mathrm{g} / \mathrm{mL}$ bovine serum albumin) along with $0.01,0.1,1,10$ and $100 \mu \mathrm{M}$ of the different aromathecins were incubated at $26^{\circ} \mathrm{C}$ during $4 \mathrm{~min}$. The control reaction performed without aromathecins contained 1\% DMSO. Reactions were stopped by adding $1 \%$ SDS (final concentration), digested with $1 \mathrm{mg} / \mathrm{mL}$ proteinase $\mathrm{K}$ at $37^{\circ} \mathrm{C}$ during $1 \mathrm{~h}$ and extracted with phenol/chloroform. DNA was separated by gel electrophoresis in $1 \%$ agarose containing $0.1 \mu \mathrm{g} / \mathrm{mL}$ ethidium bromide in $0.1 \mathrm{M}$ Tris borate EDTA buffer $(\mathrm{pH} 8.0)$ at $4 \mathrm{~V} / \mathrm{cm}$ for $16 \mathrm{~h}$. Gels were visualized with UV illumination.

\section{CPT resistant strain generation}

The CPT resistant strain used in this work was generated exposing $L$. infantum promastigotes to increased concentrations of CPT, from 0.1 to the solubility limit of the compound, $20 \mu \mathrm{M}$ in the case of CPT. Parasites were grown at $26^{\circ} \mathrm{C}$ in M199 medium supplemented as described previously, each culture being inoculated at an initial density of $10^{6}$ cells $/ \mathrm{mL}$. The promastigotes cultured in liquid medium in the presence of $20 \mu \mathrm{M} \mathrm{CPT}$, were plated on semisolid M199 medium containing $20 \mu \mathrm{M}$ CTP in order to select a single colony.

\section{Abbreviations \\ CanL: Canine leishmaniasis; CPT: Camptothecin; iRFP: infraRed Fluorescent Protein; LTopIB: Leishmania topoisomerase IB; MDR-1: Multiple Drug Resistance protein 1; SI: Selectivity Index; TopIB: DNA topoisomerases IB}

\section{Acknowledgements}

Not applicable.

\begin{abstract}
Authors' contribution
RBF, YPP and RMR conceived and designed the study. YPP and RBF drafted the manuscript and CGC, BDA and RAV performed the experiments and analyzed the data. MC provided aromathecins from its collection and edited the manuscript. All authors read and approved the final draft.

\section{Funding}

This research had the financial support of: Ministerio de Economía y Competitividad (MINECO, AEI, FEDER, UE) [MINECO: AGL2016-79813-C2-1R, SAF2017-83575-R].

Junta de Castilla y León cofinanced by FEDER UE [LE020P17, Grant UIC108]. The funding body does not participate in the design of the study; collection, analysis and interpretation of data and in writing the manuscript.
\end{abstract}

\section{Availability of data and materials}

The datasets used and/or analysed during the current study are available from the corresponding author on reasonable request.

\section{Ethics approval and consent to participate}

All protocols described in this work were approved by the Animal Care Committee of the University of Leon, project license SAF2017-83575-R It complies with European Union Legislation (2010/63/UE) and Spanish Act (RD 53/2013).

Consent for publication

Not applicable.

\section{Competing interests}

The authors declare that they have no competing interests.

\section{Author details}

'Departamento de Ciencias Biomédicas, Universidad de León, Campus de Vegazana s/n; 24071 León (SPAIN), León, Spain. ²Department of Medicinal Chemistry, and Molecular Pharmacology, College of Pharmacy, and The Purdue Center for Cancer Research, Purdue University, Lafayette, Indiana, USA.

Received: 26 July 2019 Accepted: 23 October 2019

Published online: 09 November 2019

\section{References}

1. Miró G, Petersen C, Cardoso L, Bourdeau P, Baneth G, Solano-Gallego L, Pennisi MG, Ferrer L, Oliva G. Novel areas for prevention and control of canine leishmaniosis. Trends Parasitol. 2017;33:718-30.

2. Reguera RM, Morán M, Pérez-Pertejo Y, García-Estrada C, Balaña-Fouce R. Current status on prevention and treatment of canine leishmaniasis. Vet Parasitol. 2016;227:98-114

3. Champoux JJ. DNA topoisomerases: structure, function, and mechanism. Annu Rev Biochem. 2001;70:369-413.

4. Balaña-Fouce R, Alvarez-Velilla R, Fernández-Prada C, García-Estrada C, Reguera RM. Trypanosomatids topoisomerase re-visited. New structural findings and role in drug discovery. Int J Parasitol Drugs Drug Resist. 2014;4: 326-37.

5. Cushman M, Jayaraman M, Vroman JA, Fukunaga AK, Fox BM, Kohlhagen G, Strumberg D, Pommier $Y$. Synthesis of new indeno $[1,2-c]$ isoquinolines: cytotoxic non-camptothecin topoisomerase I inhibitors. J Med Chem. 2000; 43:3688-98.

6. Burton JH, Mazcko C, LeBlanc A, Covey JM, Ji J, Kinders RJ, Parchment RE, Khanna C, Paoloni M, Lana S, Weishaar K, London C, Kisseberth W, Krick E, Vail D, Childress M, Bryan JN, Barber L, Ehrhart EJ, Kent M, Fan T, Kow K, Northup N, Wilson-Robles H, Tomaszewski J, Holleran JL, Muzzio M, Eiseman J, Beumer JH, Doroshow JH, Pommier Y. NCl comparative oncology program testing of non-camptothecin indenoisoquinoline topoisomerase I inhibitors in naturally occurring canine lymphoma. Clin Cancer Res. 2018;24: $5830-40$.

7. Bakshi RP, Sang D, Morrell A, Cushman M, Shapiro TA. Activity of indenoisoquinolines against African trypanosomes. Antimicrob Agents Chemother. 2009:53:123-8

8. Prada CF, Alvarez-Velilla R, Balaña-Fouce R, Prieto C, Calvo-Álvarez E, Escudero-Martínez JM, Requena JM, Ordóñez C, Desideri A, Pérez-Pertejo Y, Reguera RM. Gimatecan and other camptothecin derivatives poison Leishmania DNA-topoisomerase IB leading to a strong leishmanicidal effect. Biochem Pharmacol. 2013:85:1433-40.

9. Cagir A, Jones SH, Gao R, Eisenhauer BM, Hecht SM. Luotonin a; a naturally occurring human DNA topoisomerase I poison. J Am Chem Soc. 2003;125: 13628-9.

10. Xiao X, Antony S, Pommier Y, Cushman M. Total synthesis and biological evaluation of 22-hydroxyacuminatine. J Med Chem. 2006;49:1408-12.

11. Cinelli MA, Morrell A, Dexheimer TS, Scher ES, Pommier Y, Cushman M. Design, synthesis, and biological evaluation of 14-substituted aromathecins as topoisomerase I inhibitors. J Med Chem. 2008;51:4609-19.

12. Cinelli MA, Cordero B, Dexheimer TS, Pommier Y, Cushman M. Synthesis and biological evaluation of 14-(aminoalkyl-aminomethyl) aromathecins as topoisomerase I inhibitors: investigating the hypothesis of shared structureactivity relationships. Bioorg Med Chem. 2009;17:7145-55.

13. Cinelli MA, Morrell AE, Dexheimer TS, Agama K, Agrawal S, Pommier Y, Cushman M. The structure-activity relationships of A-ring-substituted aromathecin topoisomerase I inhibitors strongly support a camptothecinlike binding mode. Bioorg Med Chem. 2010;18:5535-52. 
14. Nenortas NP, Cinelli MA, Morrell AE, Cushman M, Shapiro TA. Activity of aromathecins against African trypanosomes. Antimicrob Agents Chemother. 2018;62:e00786-18.

15. BoseDasgupta S, Ganguly A, Roy A, Mukherjee T, Majumder HK. A novel ATP-binding cassette transporter, ABCG6 is involved in chemoresistance of Leishmania. Mol Biochem Parasitol. 2008;158:176-88.

16. Marquis JF, Hardy I, Olivier M. Topoisomerase I amino acid substitutions, Gly185Arg and Asp325Glu, confer camptothecin resistance in Leishmania donovani. Antimicrob Agents Chemother. 2005:49:1441-6.

17. Antony S, Agama KK, Miao ZH, Takagi K, Wright MH, Robles Al, Varticovski L, Nagarajan M, Morrell A, Cushman M, Pommier Y. Novel indenoisoquinolines NSC 725776 and NSC 724998 produce persistent topoisomerase I cleavage complexes and overcome multidrug resistance. Cancer Res. 2007;67:10397-405.

18. Calvo-Álvarez E, Stamatakis K, Punzón C, Álvarez-Velilla R, Tejería A, Escudero-Martínez JM, Pérez-Pertejo Y, Fresno M, Balaña-Fouce R, Reguera RM. Infrared fluorescent imaging as a potent tool for in vitro, ex vivo and in vivo models of visceral leishmaniasis. PLoS Negl Trop Dis. 2015;9: e0003666.

19. Tejería A, Pérez-Pertejo Y, Reguera RM, Balaña-Fouce R, Alonso C, Gonzalez M, Rubiales G, Palacios F. Substituted 1,5-naphthyridine derivatives as novel antileishmanial agents. Synthesis and biological evaluation. Eur J Med Chem. 2018:152:137-47.

20. Villa H, Otero Marcos AR, Reguera RM, Balaña-Fouce R, García-Estrada C, Pérez-Pertejo Y, Tekwani BL, Myler PJ, Stuart KD, Bjornsti MA, Ordóñez D. A novel active DNA topoisomerase I in Leishmania donovani. J Biol Chem. 2003;278:3521-6.

\section{Publisher's Note}

Springer Nature remains neutral with regard to jurisdictional claims in published maps and institutional affiliations.

Ready to submit your research? Choose BMC and benefit from:

- fast, convenient online submission

- thorough peer review by experienced researchers in your field

- rapid publication on acceptance

- support for research data, including large and complex data types

- gold Open Access which fosters wider collaboration and increased citations

- maximum visibility for your research: over $100 \mathrm{M}$ website views per year

At $\mathrm{BMC}$, research is always in progress.

Learn more biomedcentral.com/submissions 